\title{
Equatorial ionospheric disturbance observed through a transequatorial HF propagation experiment
}

\section{T. Maruyama and M. Kawamura}

National Institute of Information and Communications Technology, Koganei, Tokyo, 184-8795, Japan

Received: 1 September 2005 - Revised: 9 February 2006 - Accepted: 21 April 2006 - Published: 3 July 2006

Part of Special Issue "The 11th International Symposium on Equatorial Aeronomy (ISEA-11), Taipei, May 2005"

\begin{abstract}
A transequatorial radio-wave propagation experiment at shortwave frequencies (HF-TEP) was done between Shepparton, Australia, and Oarai, Japan, using the radio broadcasting signals of Radio Australia. The receiving facility at Oarai was capable of direction finding based on the MUSIC (Multiple Signal Classification) algorithm. The results were plotted in azimuth-time diagrams (AT plots). During the daytime, the propagation path was close to the great circle connecting Shepparton and Oarai, thus forming a single line in the AT plots. After sunset, off-great-circle paths, or satellite traces in the AT plot, often appeared abruptly to the west and gradually returned to the great circle direction. However, there were very few signals across the great circle to the east. The off-great-circle propagation was very similar to that previously reported and was attributed to reflection by an ionospheric structure near the equator. From the rate of change in the direction, we estimated the drift velocity of the structure to range mostly from 100 to $300 \mathrm{~m} / \mathrm{s}$ eastward. Multiple instances of off-great-circle propagation with a quasi-periodicity were often observed and their spatial distance in the east-west direction was within the range of large-scale traveling ionospheric disturbances (LS-TIDs). Off-great-circle propagation events were frequently observed in the equinox seasons. Because there were many morphological similarities, the events were attributed to the onset of equatorial plasma bubbles.
\end{abstract}

Keywords. Ionosphere (Equatorial ionosphere; Ionospheric irregularities) - Radio science (Ionospheric propagation)

\section{Introduction}

After the pioneering work done by Röttger (1973), not much attention has been paid to high-frequency transequatorial

Correspondence to: T. Maruyama

(tmaru@nict.go.jp) propagation (HF-TEP) experiments using a direction finding technique in ionospheric studies, except for a short campaign at a Peruvian longitude (Flaherty et al., 1996). However, it was shown early on that HF-TEP observations can be used for remote detection of equatorial ionospheric disturbances. Comparing the off-great-circle propagation along the Lindau-Tsumeb transequatorial path and the radar backscatter at Nairobi, Kelleher and Röttger (1973) found a high correlation between the occurrences of these two events. Later, Röttger (1976) suggested that a macro-scale structure of the equatorial ionosphere that causes off-great-circle propagation is related to the formation of equatorial spread-F (ESF) irregularities through a spatial resonance mechanism that amplifies traveling ionospheric disturbances.

The basic mechanism of the ESF onset came to be known as the Rayleigh-Taylor (R-T) instability (e.g. Fejer and Kelley, 1980). The nonlinear evolution of the Rayleigh-Taylor instability forms density depleted plasma bubbles, which intrude into the topside and extend along the magnetic field line over several thousand kilometers. Satellite in-situ observations revealed density biteouts in the topside ionosphere. Tsunoda et al. (1982) showed that the local uplifts observed by east-west scanning radar are vertically connected with topside ion density biteouts measured by the Atmospheric Explorer-E (AE-E) satellite. Weber et al. (1982) related the topside density biteouts measured by the AE-E satellite to bottomside signatures through airglow and ionosonde measurements. Local uplifts of bottomside isodensity surfaces cause a 630-nm airglow depletion and oblique ionosonde echoes from local electron density gradients (Weber et al., 1980). Airglow depletion appears as a band with an eastwest dimension ranging from 50 to $200 \mathrm{~km}$, and is elongated in the direction of the magnetic meridian over $3000 \mathrm{~km}$ or more (e.g. Weber et al., 1980; Mendillo and Baumgardner, 1982). A recent nonlinear simulation of R-T instability revealed a three-dimensional structure of a plasma depleted region, which is associated with bottomside uplifts along the

Published by Copernicus GmbH on behalf of the European Geosciences Union. 


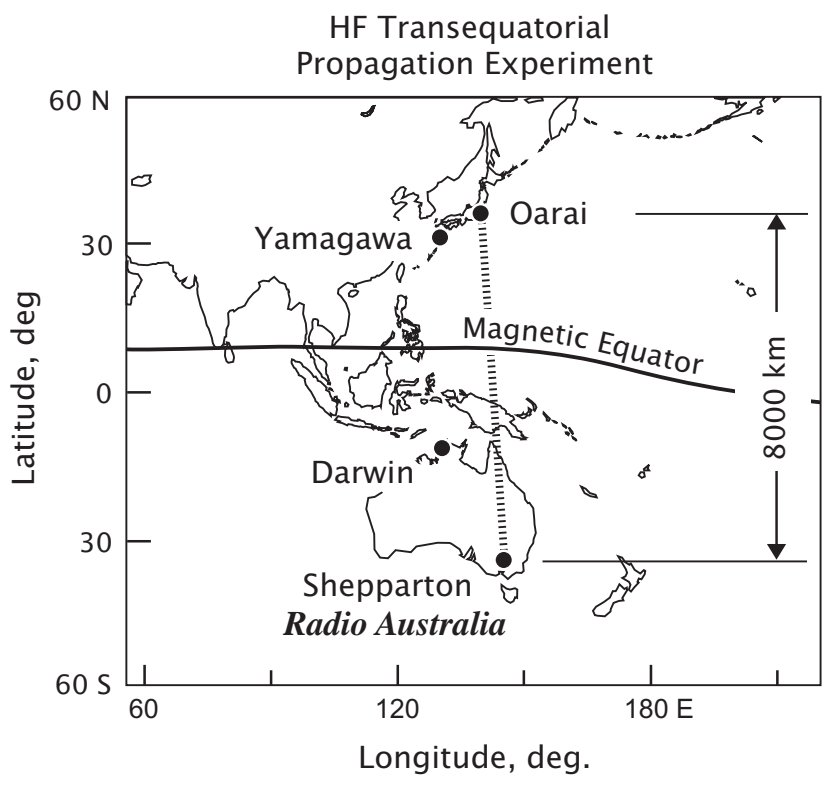

Fig. 1. Geometry of the HF transequatorial propagation experiment between Shepparton, Australia and Oarai, Japan. A VHF transequatorial propagation experiment between Darwin and Yamagawa was reported in 1980 .

magnetic meridian (Keskinen et al., 2003). The modulated isodensity surfaces, a bottomside signature of plasma bubbles, would change HF radio wave propagation paths because of local ionospheric tilt. Thus, HF-TEP experiments should reveal the local uplifting of the ionospheric layer associated with plasma bubbles.

One major difficulty in transequatorial propagation experiments is finding a suitable location pair in the two hemispheres near the conjugate points. We located the MUSIC (Multiple Signal Classification) directional-finder (Schmidt, 1986; Hawlitschka, 2006) in Oarai, $100 \mathrm{~km}$ northeast of Tokyo, in our propagation experiments. The MUSIC algorithm is applicable to any kind of radio wave modulation. Thus, no dedicated transmitters were required if a radio broadcasting station already existed. Radio Australia is a station in Shepparton, $180 \mathrm{~km}$ north of Melbourne, Australia, that transmits HF signals, $24 \mathrm{~h}$ a day.

\section{Measurement setup}

Broadcasting signals of Radio Australia transmitted from Shepparton $\left(145.3^{\circ} \mathrm{E}, 36.2^{\circ} \mathrm{S}\right)$ were received at Oarai $\left(140.6^{\circ} \mathrm{E}, 36.3^{\circ} \mathrm{N}\right)$. The transmitting and receiving stations were aligned along the $140-145^{\circ} \mathrm{E}$ meridian separated by $8000 \mathrm{~km}$ and the great circle direction from Oarai to Shepparton is $4.3^{\circ}$ from due south to east, as shown in Fig. 1 . The Oarai MUSIC HF direction finder consisted of seven crossed-loop antennas, each $2 \mathrm{~m}$ in diameter, aligned in a 60-m diameter circle. The azimuth and elevation angle

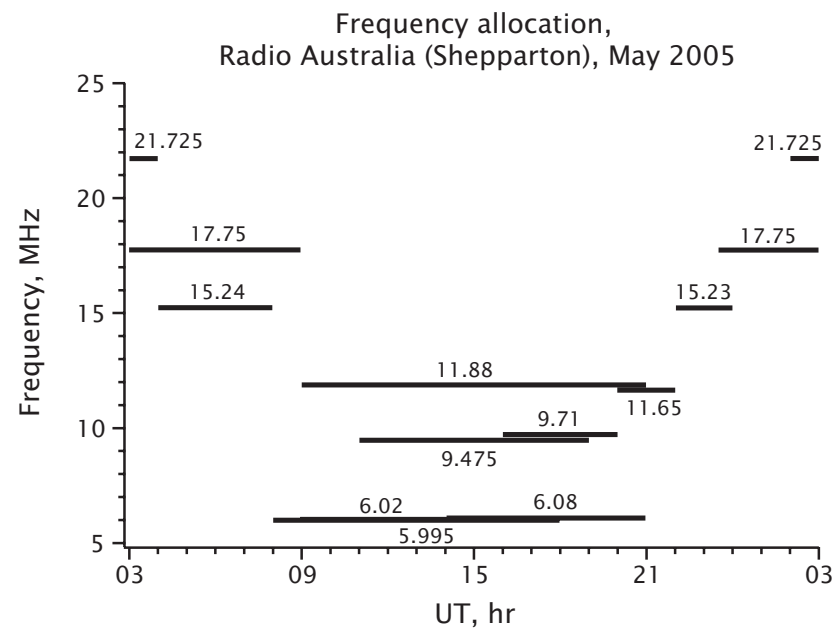

Fig. 2. Frequency allocation of Radio Australia (Shepparton) as of May 2005. The frequencies were subject to change depending on the season and solar activity.

resolutions of the direction of arrival (DOA) were $1^{\circ}$ and up to three ray directions were simultaneously resolved with a time resolution of $0.5 \mathrm{~s}$. In general, radio broadcasting signals are transmitted simultaneously at several frequencies and those frequencies are changed depending on the local time and season. Thus, the receiving frequencies were scanned, i.e. the azimuth and elevation angles were measured for $8 \mathrm{~s}$ when signals were received, and then the measurement was moved to the next frequency. An example of frequency allocation is shown in Fig. 2.

\section{Results}

Our major interest was the off-great-circle propagation caused by an ionospheric tilt associated with large-scale structures. We analyzed the temporal variation of the azimuth angle of the DOA. Results were plotted in azimuthtime diagrams (AT plots), as shown in Fig. 3. This example was from the day of 21-22 April 2003, and local midnight is centered. The angle was measured from due south to east or west. In HF broadcasting, several stations generally use the same frequencies for transmission, which is undesirable for the current experiment. Fortunately, most stations are in the Northern Hemisphere and interference from these sources can be easily recognized by eye in the AT plots. Points with an azimuth angle greater than $60^{\circ}$ to the west in Fig. 3 and other AT plots (Figs. 4, 5, and 7) are from such sources of interference.

During the daytime (UT $+09 \mathrm{~h} 20 \mathrm{~min}$ is mean local time at $140^{\circ} \mathrm{E}$ ), the DOA of Radio Australia was close to the great circle, forming a single horizontal trace near $4^{\circ} \mathrm{E}$ in the AT plot. At about the sunset terminator, the DOA shifted westward reaching due south at 08:40 UT and returned to the 


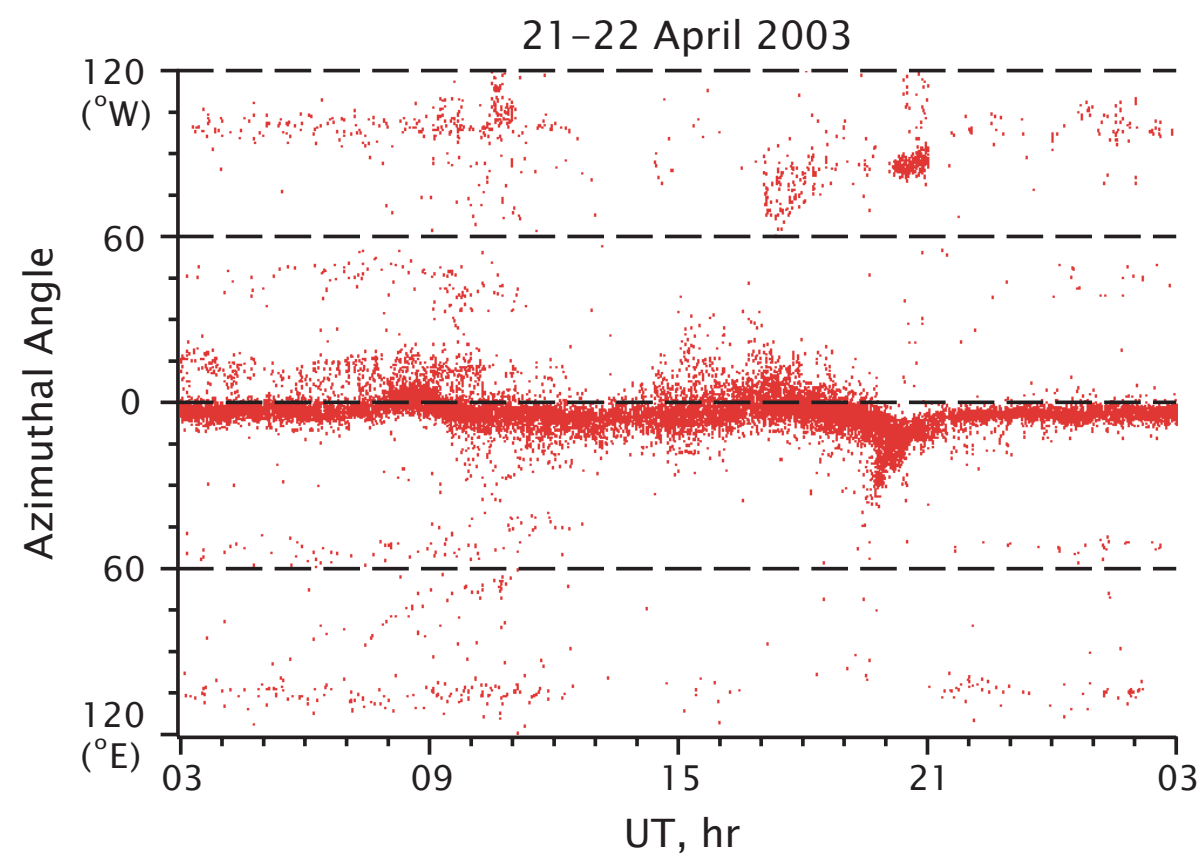

Fig. 3. Azimuth-time plot of incident rays on 21-22 April 2003.

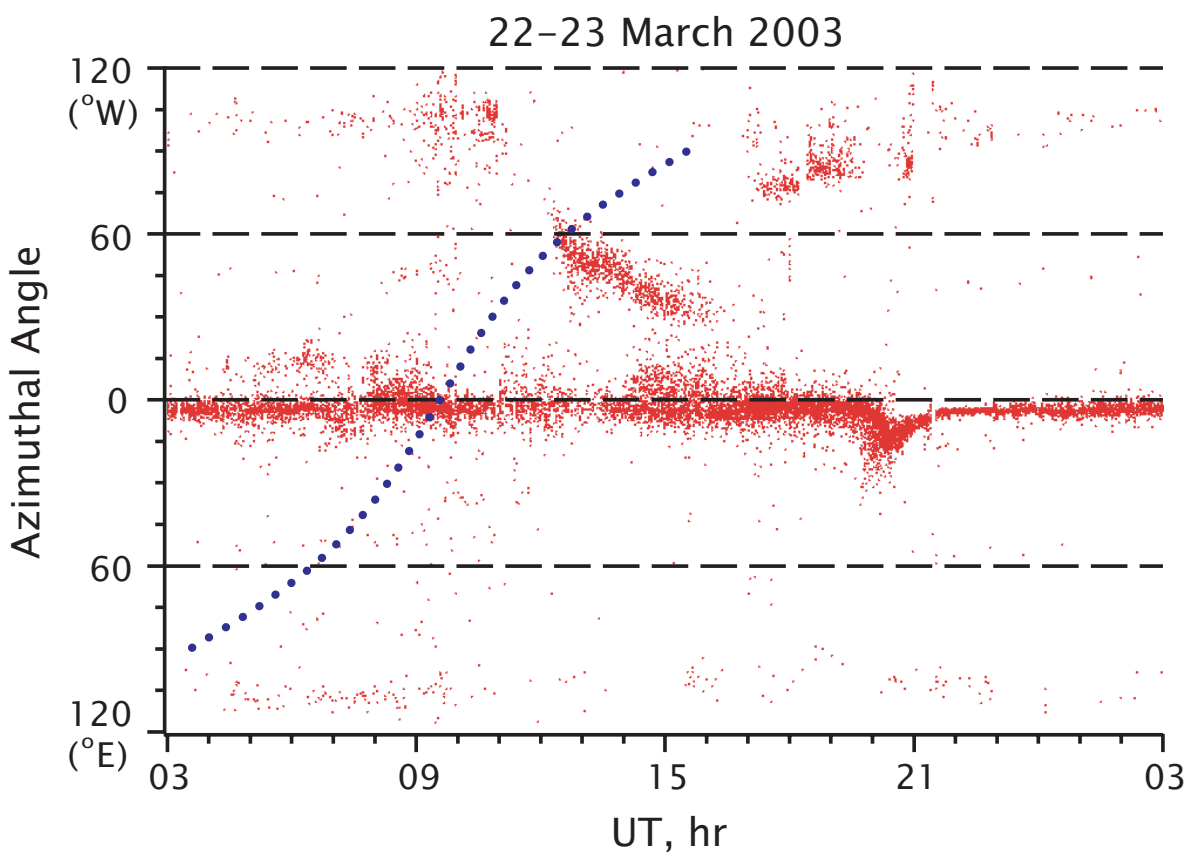

Fig. 4. The same as for Fig. 3, but for 22-23 March 2003. The dotted curve means a constant local time condition at the reflection point.

normal direction by 09:30 UT. After this, the trace shifted eastward and gradually returned to the normal direction through the night. This pattern was basically repeated every day and we interpreted it as a terminator effect. Similarly, near the sunrise terminator, the ray direction shifted eastward and gradually returned to the normal daytime direction. This pattern was also repeated every day.
Figure 4 shows an example of a satellite trace observed on 22-23 March 2003, in addition to the above-mentioned diurnal pattern of the DOA. The satellite trace abruptly appeared at 12:00 UT in the direction of $60^{\circ}$ to the west and moved eastward at a constant rate for about $3.5 \mathrm{~h}$.

A more spectacular event observed on 24-25 March 2004 is shown in Fig. 5. This figure shows multiple satellite traces 


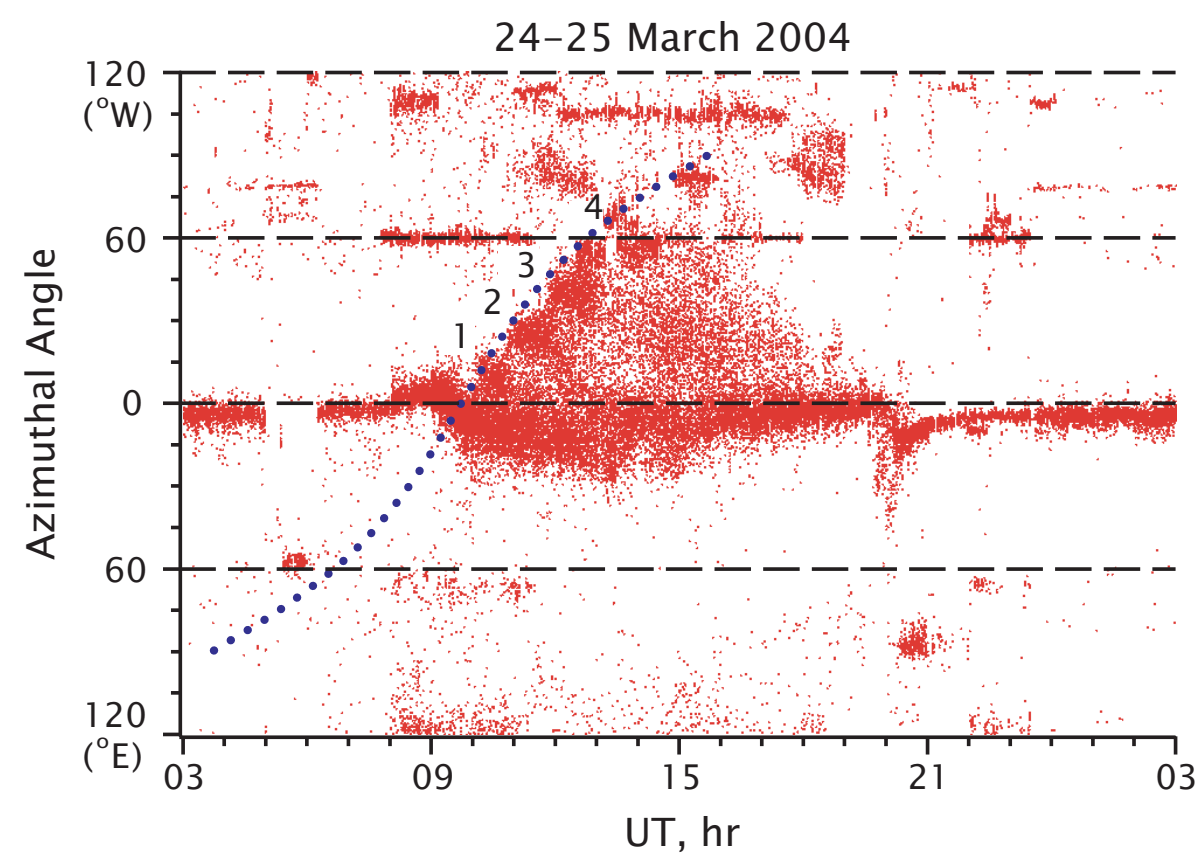

Fig. 5. The same as for Fig. 3, but for 24-25 March 2004.

that appeared in the west, each similar to the satellite trace in Fig. 4 but of a shorter duration. At least four traces lasting about one hour were observed (numbered from 1 to 4 ). They were nearly evenly spaced in the diagram and the start position shifted westward with time. However, the individual traces were tilted eastward. A blob between numbers 3 and 4 was probably interference, since it appeared every day during these months irrespective of the satellite traces. Each satellite trace kept its shape for about $1 \mathrm{~h}$, and then became diffused. In addition, the main trace was somewhat scattered during the night compared with the previous two nights.

\section{Discussion}

\subsection{Terminator effect}

First, we discuss the DOA deviation from the great circle direction that repeatedly appeared near the sunset and sunrise terminators. At the sunset terminator, the layer height rapidly rises due to the evening enhancement of the eastward electric field (e.g. Fejer et al., 1989), in addition to the rapid chemical recombination in the bottomside. The equatorial eastward electric field is enhanced for about two hours before its reversal near 19:30 LT. During this period, the layer height increases by several tenths to $100 \mathrm{~km}$ or more, although the amount greatly varies with the season and solar activity (Fejer et al., 1989). If the local time pattern of changes in the layer height at a given location is equivalent to the longitudinal structure over the equator at a given instance, the bottomside isodensity surface will tilt over $3000 \mathrm{~km}$, reaching higher altitudes in the east, thus causing the shift of the DOA to the west. When the layer reaches the maximum altitude in other words, when the vertical drift direction reverses - the isodensity surface becomes horizontal and the DOA returns to the great circle direction. After that, the DOA shifts to the east because of the reversed tilt of the layer caused by the persistent downward drift. Through the night, the DOA returns to the great circle direction when the layer height reaches the chemical equilibrium state.

Near sunrise, new ionization starts in the east in the lower part of the ionosphere, which results in a tilt of the isodensity surface with a lower altitude in the east. Thus, the DOA of the incident ray shifts east.

\subsection{Onset time of satellite traces}

By assuming that the radio waves forming the satellite traces are reflected by the bottomside structure of plasma bubbles near the equator, we relate the points in the AT plot to the local time at the reflection point. The bottomside signature of plasma bubbles is a local uplift elongated along the magnetic meridian over several thousand kilometers with an east-west width of about 50-200 km (Tsunoda et al., 1982; Weber et al., 1982; Mendillo and Baumgardner, 1982). In this paper, we use the term plasma bubble for this bottomside signature. The magnetic declination angle near the equator at Southeast Asian longitudes is close to zero. We thus consider a northsouth aligned linear structure model (Fig. 6a). As Shepparton and Oarai are in almost geographically conjugate locations, we assume that the reflection point $\mathrm{P}$ lies at the geographic equator. A great circle passing through $\mathrm{P}$ and Oarai 
is drawn and the azimuth angle $\alpha$ is related to the longitude of $P$. The longitudinal distance between Oarai's meridian and $\mathrm{P}$, together with UT when a signal is received, gives the local time at the reflection point or the location of the plasma bubble. In the AT diagram, the locus of the points fitting a constant local time condition at the reflection point is an $\mathrm{S}$ curve (Fig. 6b). The time (UT) where the S curve crosses $\alpha=0^{\circ}$ in the diagram is the local time (LT) at Oarai's meridian; i.e. $\mathrm{LT}=\mathrm{UT}+09 \mathrm{~h} 20 \mathrm{~min}$ (corresponding to the longitude of $140^{\circ} \mathrm{E}$ ).

In Figs. 4 and 5, the line of constant local time (the $\mathrm{S}$ curve) that contacts the satellite traces crosses the horizontal line of $\alpha=0^{\circ}$ near 09:45 UT, which corresponds to 19:05 LT. To generalize, we plotted all data points for the days on which satellite traces were observed during March 2003 (i.e., 23 of 31 nights) together in Fig. 7. The upper-left envelope of the satellite traces, west of the main trace, coincides well with the S curve, i.e. satellite traces started at the same local time. Recently, beam steerable Equatorial Atmosphere Radar (EAR) at a longitude of $100^{\circ} \mathrm{E}$ revealed that the onset time of radar backscattering from a plasma bubble is confined to a narrow time slot after sunset (Yokoyama et al., 2004). A white dotted curve showing the mean diurnal variation of the main trace is also plotted in Fig. 7. The two dotted curves intersect at the time when the DOA of the main trace returned to the great circle direction after the westward deviation caused by the evening enhancement of the upward $\boldsymbol{E} \times \boldsymbol{B}$ drift. That is, the satellite traces started when the layer vertical drift reversed. This is consistent with radar backscatter plumes that often start when the layer is at its peak height or the layer is descending (Argo and Kelley, 1986). From another perspective, the fact that the starting point of the satellite traces was aligned with the $\mathrm{S}$ curve, a constant local time condition at the geographic equator, provides evidence supporting the validity of our assumption regarding the reflection points at the geographic equator. If the reflection points were located at a latitude higher (lower) than the geographic equator, $\alpha$ should have been large (small) for the same northsouth aligned plasma bubble.

In Fig. 7, there are very few traces to the east of the main trace (the lower half of the plot). A similar east-west asymmetry of HF-TEP radio reception rate is reported by Röttger (1973), although the degree of asymmetry looked stronger in our observations. One possible explanation is the eastwest asymmetry of the structure. Tsunoda (1983) found that plumes of radar backscatter from ESF start at the west wall of the upwellings.

\subsection{Drift velocity and spatial structure}

Satellite traces of the off-great-circle propagation in AT plots moved eastward. The quantity we observed was the azimuth angle of the DOA, $\alpha$, which was related to the location of plasma bubbles, as illustrated in Fig. 6. For the event of 22-23 March 2003, we estimated graphically the drift ve- (a)

(b)
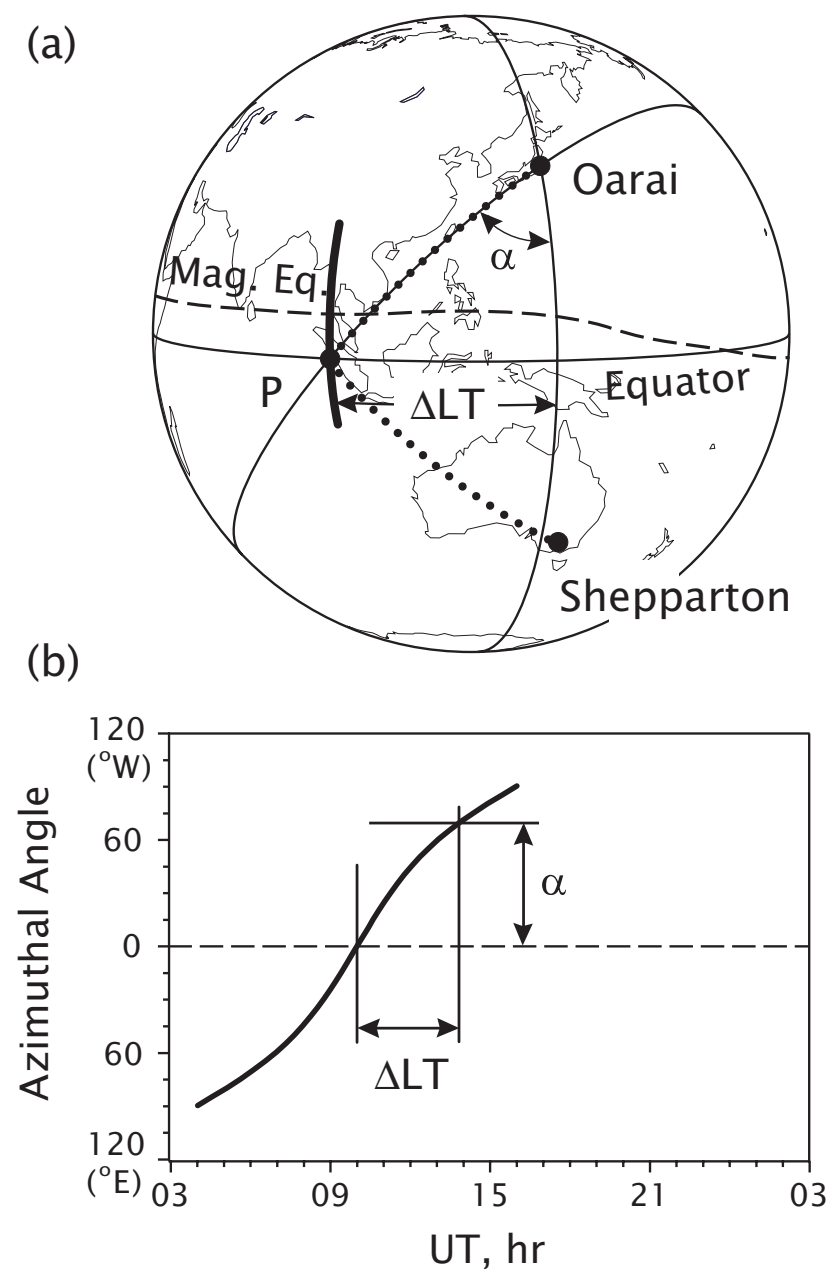

Fig. 6. Relationship between the direction of arrival of the incident ray $(\alpha)$ and the reflection point $(\mathrm{P})$ at the geographic equator. The dotted curve represents the ray path reaching Oarai.

locity using the S-curve slider, as shown in Fig. 8. In the figure, the thick slanted line replicates the satellite trace and we put two reference points on it. Two dotted S curves were drawn to obtain the local time at the reflection points. The local time difference at the reflection points was $92 \mathrm{~min}$, while the actual elapsed time was $60 \mathrm{~min}$. The excess local time of $32 \mathrm{~min}$ was due to the eastward movement of the reflection point, which corresponded to $8^{\circ}$ in longitude or $890 \mathrm{~km}$. Thus, the drift velocity was calculated as $247 \mathrm{~m} / \mathrm{s}$. In this process, a different pair of reference points yields a different velocity because the tangent of the $\mathrm{S}$ curve at the reference points becomes shallower with any divergence from the horizontal line of $\alpha=0^{\circ}$. A reference point pair closer to the line of $\alpha=0^{\circ}$ yields a lower velocity.

We calculated the drift velocities for the satellite traces observed in the high occurrence season around the March equinox by applying this method. In general, the nighttime bulk zonal drift velocities of plasma drift and neutral wind 


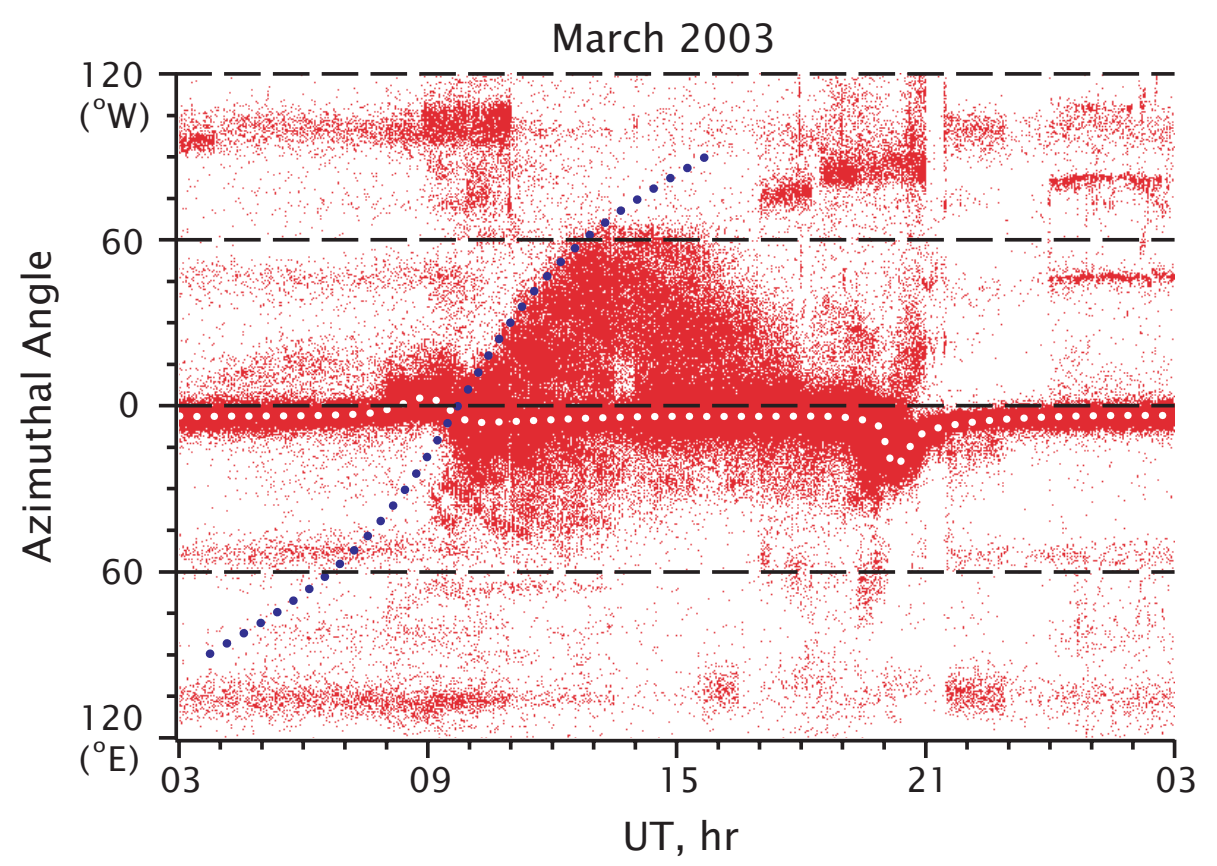

Fig. 7. Azimuth angle of incident rays for 23 days on which satellite traces were observed in March 2003. All data points were put together in one diagram. The white dotted curve is the averaged main trace.

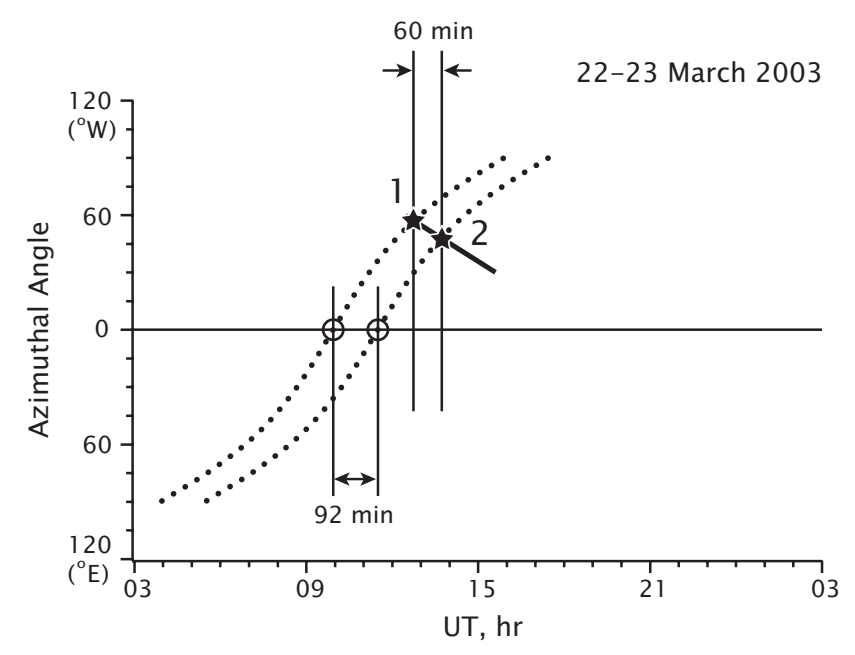

Fig. 8. Graphical estimation of zonal drift velocity (see the text for details).

near the equator vary with local time (Fejer et al., 1985). We chose reference points where one was near the start of the satellite trace and the other was $60 \mathrm{~min}$ to the right, i.e. drift velocities were determined for about 19:30-20:30 LT at the reflection point. Figure 9a shows the drift velocity for February to April over three years, while Fig. 9b shows it for the month of the largest occurrence frequency only (March) and Fig. 9c shows it for the other months (February and April). The drift velocity depended on the month, becoming higher during the high occurrence month, with a median value of about $220 \mathrm{~m} / \mathrm{s}$ and lower during the other months, with a median of about $190 \mathrm{~m} / \mathrm{s}$. The median value of the drift velocity over the three months was $200 \mathrm{~m} / \mathrm{s}$ (Fig. 9a). In all cases, the drift velocity was higher than the average plasma drift velocity obtained by the Jicamarca radar (Fejer et al., 1985), which was about $150 \mathrm{~m} / \mathrm{s}$ at 20:00 LT for the solar maximum period. The neutral wind velocity obtained by the DE-2 satellite for similar conditions was somewhat higher than the Jicamarca radar results (Fejer et al., 1985), but still it was lower than our drift velocity.

Space-based far ultraviolet (FUV) optical measurements from an imager aboard the IMAGE satellite revealed that the zonal drift velocity of equatorial plasma bubbles largely depends on the longitude (Immel et al., 2004). The highest velocity was $9.9^{\circ} / \mathrm{h}(306 \mathrm{~m} / \mathrm{s})$ around the Indian sector, while the mean speed was $6.5^{\circ} / \mathrm{h}(200 \mathrm{~m} / \mathrm{s})$. Lin et al. (2005) discussed the difference between the plasma bubble drift velocities based on the IMAGE FUV observations and the plasma drift velocities obtained from the ROCSAT-1 satellite, which are much lower than the FUV bubble velocity. Our estimated drift velocity based on the HF-TEP observation is close to the IMAGE results.

In the calculation of drift velocities described in this paper, we assumed that the reflection point $\mathrm{P}$ lay at the geographic equator. When the reflection point was assumed to be at the magnetic equator, which is about $8.5^{\circ}$ northward of the geographic equator at longitudes from $110-140^{\circ} \mathrm{E}$, we obtained a lower velocity by some $30 \mathrm{~m} / \mathrm{s}$. To reach a definitive 


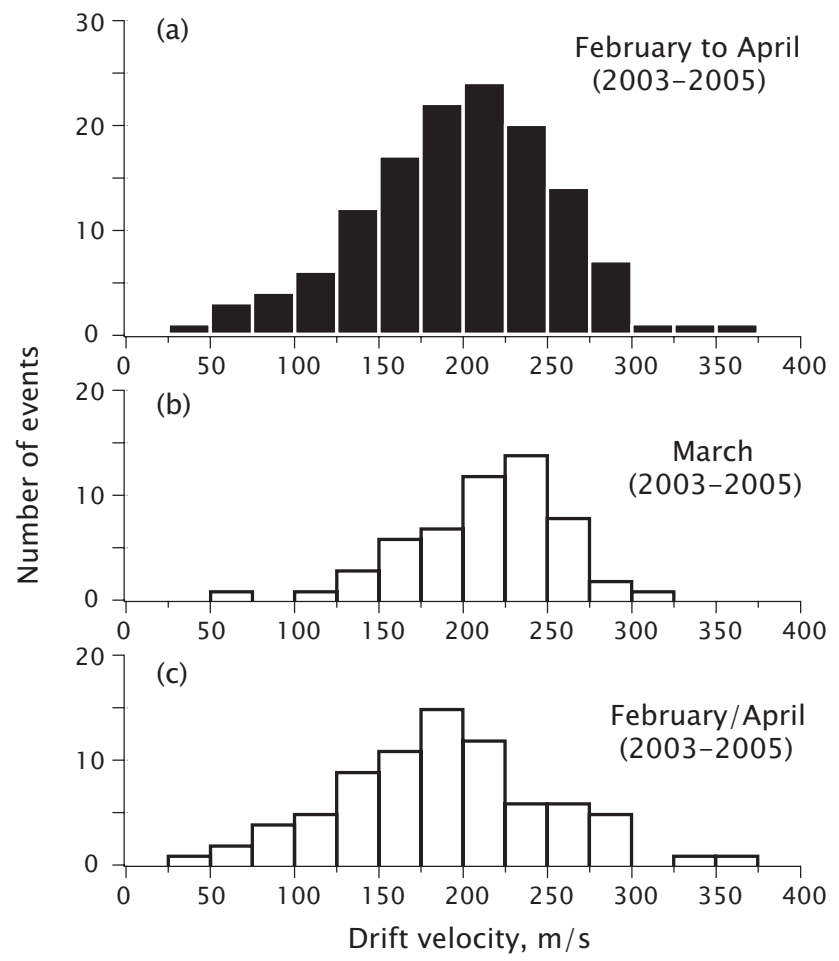

Fig. 9. Zonal drift velocity for (a) the February to April period from 2003 to 2005, (b) March (high occurrence month) only, and (c) February and April.

conclusion regarding the drift velocity and to support further discussion on the difference in the background plasma drift velocity, we need to perform more propagation experiments between magnetically conjugate points while obtaining simultaneous ground-based observations near the reflection point.

For the multiple events on 24-25 March 2004 in Fig. 5, the estimated drift velocity was $232 \mathrm{~m} / \mathrm{s}$, although this estimation was not very accurate, since the traces were blob-like rather than lines. Using this velocity, we then estimated the wavelength of the periodic satellite traces. The local times of the onset of these traces were the same, and the onset time (UT) was delayed by $50 \mathrm{~min}$ for each. In $50 \mathrm{~min}$, the onset location moved $1390 \mathrm{~km}$ westward. During the same time, the first bubble drifted $700 \mathrm{~km}$ eastward. Thus, we obtained a separation between the two bubbles of $2090 \mathrm{~km}$, which is in the range of large-scale traveling ionospheric disturbances (LS-TIDs). This is fairly large compared with the horizontal wavelength of equatorial patches investigated by Röttger (1973), in which the disturbances were in the range of medium-scale traveling ionospheric disturbances (MSTIDs). The IMAGE FUV observations also show a separation distance between airglow depletion bands in a range from 400 to $1100 \mathrm{~km}$. In our HF propagation experiment, we often observed diffused traces, like the late local time section and main trace shown in Fig. 5. Most probably, mul- tiple bubbles with a small separation caused these diffused traces. Another explanation is the bifurcation of bubbles, i.e. the high-latitude section of the airglow depletions split into two or more bands (Mendillo and Baumgardner, 1982). Although we assumed a specular reflection for the HF radio propagation, if the local uplifts contained smaller scale structures, a scattering mechanism cannot be excluded. The equatorial ionospheric structure should have a wide spectrum and different techniques are likely to be sensitive to different wavelengths.

\subsection{Seasonal variation}

Figure 10 shows the monthly occurrence frequency of satellite traces and the monthly mean F10.7 solar flux index. (The vertical axis shows the number of days on which one or more satellite traces were observed in each month.) Occurrences were mostly confined to the months from February to April with a secondary peak around October. Seasonal variation in the occurrence of equatorial irregularities is known to vary with longitude. At the longitudes where the magnetic declination angle is small, like Southeast Asia to India, ESF and plasma bubbles tend to be active around the equinoctial seasons (Maruyama and Matuura, 1984; Burke et al., 2004a, b). Similar equinoctial occurrence maxima of gigahertz equatorial scintillations were reported by Paulson (1981) and Fang and Liu (1983).

In addition to the general equinoctial maxima, a March/September asymmetry can be seen in Fig. 10, which was not clearly seen in the seasonal longitudinal variation diagram of density biteout occurrence at $800 \mathrm{~km}$ based on a large database of DMSP satellite observations (Burke et al., 2004a, b). The degree of asymmetry in Fig. 10 differed from year to year; strong asymmetry was observed in 2003 , but the asymmetry was much less significant in 2004. A transequatorial propagation experiment in the VHF band conducted between Darwin, Australia, and Yamagawa, Japan (see Fig. 1) also revealed equinoctial maxima and March/September asymmetry of the signal reception rate (Tanohata et al., 1980). The reception rate was higher at the March equinox than the September equinox in some years, while it was almost equal in other years. The transequatorial propagation in the VHF band is thought to be due to forward scattering by irregularities inside a plasma bubble or wave guiding by a sharp boundary of the bubble (Heron, 1981).

During the three years analyzed here, the solar activity gradually declined as seen in the change in the F10.7 index from about 130 to 80 (Fig. 10). Except for the very small number of occurrences during the September equinox in 2003, the occurrence number generally decreased. This tendency is also consistent with the climatology of plasma density biteout detection at $800 \mathrm{~km}$ altitudes by the DMSP satellite (Huang et al., 2002). 


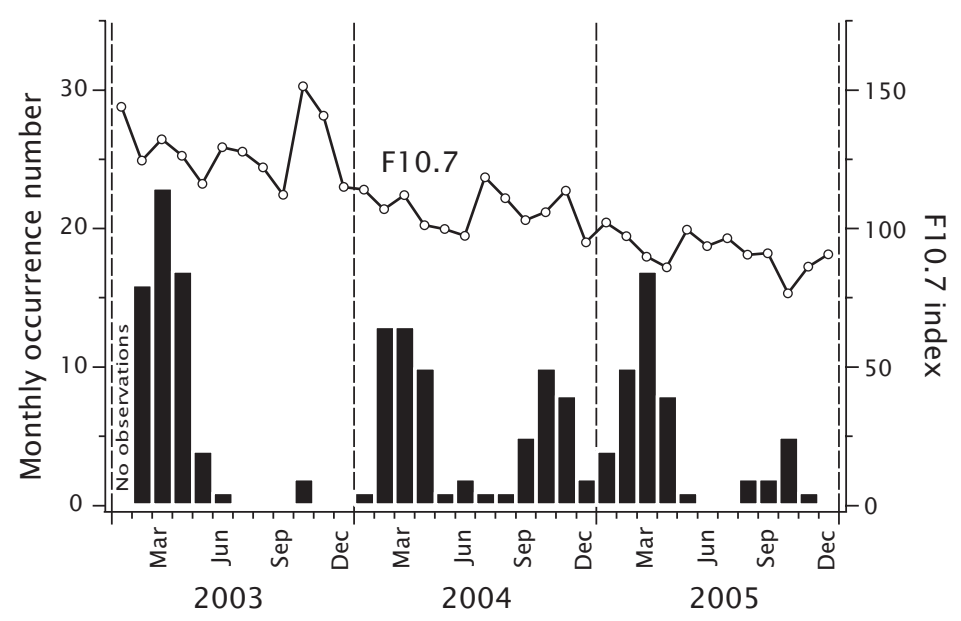

Fig. 10. Monthly occurrence of satellite trace and F10.7 solar flux index.

\section{Concluding remarks}

An HF transequatorial propagation experiment was conducted by receiving broadcasting signals of Radio Australia transmitted from Shepparton near Melbourne, Australia. Off-great-circle propagation was often observed at nighttime, and this was attributed to bottomside uplifts associated with plasma bubbles. The morphology and characteristics of those satellite traces, including the onset time, the drift velocity, the east-west asymmetry, and the seasonal variation, were consistent with a vast number of previous observations. There were, however, quantitative differences between the present results and previous ones, such as in the eastward drift velocity of the irregularities and the large wavelength of the spatial separation of multiple events. In our experiment, satellite traces were detected up to $60^{\circ}$ west of the great circle propagation direction, which enabled us to monitor the onsets of plasma bubbles and, more practically, the onsets of ionospheric scintillations in a wide upstream area of general eastward drift. This is a great advantage for monitoring space weather (which can lead to communication/navigation outages) monitoring. The analysis in this paper assumed that the reflection points lay on the geographic equator, which led to ambiguity concerning the estimated drift velocity of plasma bubbles. To overcome this problem, we need to do a propagation experiment between geomagnetically conjugate points using a dedicated transmitter at a fixed frequency throughout the day.

Acknowledgements. Topical Editor M. Pinnock thanks S. Crowley and another referee for their help in evaluating this paper.

\section{References}

Argo, P. E. and Kelley, M. C.: Digital ionosonde observations during equatorial spread F, J. Geophys. Res., 91, 5539-5555, 1986.
Burke, W. J., Huang, C. Y., Gentile, L. C., and Bauer, L.: Seasonallongitudinal variability of equatorial plasma bubbles, Ann. Geophys., 22, 3089-3098, 2004a.

Burke, W. J., Gentile, L. C., Huang, C. Y., Valladares, C. E., and $\mathrm{Su}, \mathrm{S}$. Y.: Longitudinal variability of equatorial plasma bubbles observed by DMSP and ROCSAT-1, J. Geophys. Res., 109, A12301, doi:10.1029/2004JA010583, 2004b.

Fang, D. J. and Liu, C. H.: A morphological study of gigahertz equatorial scintillations in the Asian region, Radio Sci., 18, 241252, 1983.

Fejer, B. G. and Kelley, M. C.: Ionospheric irregularities, Rev. Geophys. Space Phys., 18, 401-454, 1980.

Fejer, B. G., Kudeki, E., and Farley, D. T.: Equatorial F region zonal plasma drifts, J. Geophys. Res., 90, 12 249-12 255, 1985.

Fejer, B. G., de Paula, E. R., Batista, I. S., Bonelli, E., and Woodman, R. F.: Equatorial F region vertical plasma drifts during solar maxima, J. Geophys. Res., 94, 12 049-12 054, 1989.

Flaherty, J. P., Kelley, M. C., Seyler, C. E, and Fitzgerald, T. J.: Simultaneous VHF and transequatorial HF observations in the presence of bottomside equatorial spread F, J. Geophys. Res., 101, 26811-26818, 1996.

Hawlitschka, S.: Travelling ionospheric disturbances (TIDs) and tides observed by a super-resolution HF direction finding system, J. Atmos. Solar-Terr. Phys., 68, 568-577, 2006.

Heron, M. L.: Recent progress in transequatorial propagation - review, J. Atmos. Terr. Phys., 43, 597-606, 1981.

Huang, C. Y., Burke, W. J., Machuzak, J. S., Gentile, L. C., and Sultan, P. J.: Equatorial plasma bubbles observed by DMSP satellites during a full solar cycle: Toward a global climatology, J. Geophys. Res., 107(A12), 1434, doi:10.1029/2002JA009452, 2002.

Immel, T. J., Frey, H. U., Mende, S. B., and Sagawa, E.: Global observations of the zonal drift speed of equatorial ionospheric plasma bubbles, Ann. Geophys., 22, 3099-3107, 2004.

Kelleher, R. F. and Röttger, J.: Equatorial spread-F irregularities observed at Nairobi and on the transequatorial path LindauTsumeb, J. Atmos. Terr. Phys., 35, 1207-1211, 1973.

Keskinen, M. J., Ossakow, S. L., and Fejer, B. G.: Threedimensional nonlinear evolution of equatorial ionospheric 
spread-F bubbles, Geophys. Res. Lett., 30(16), 1855, doi:10.1029/2003GL017418, 2003.

Lin, C. S., Immel, T. J., Yeh, H.-C., Mende, S. B., and Burch, J. L.: Simultaneous observations of equatorial plasma depletion by IMAGE and ROCSAT-1 satellites, J. Geophys. Res., 110, A06304, doi:10.1029/2004JA010774, 2005.

Maruyama, T. and Matuura, N.: Longitudinal variability of annual changes in activity of equatorial spread $\mathrm{F}$ and plasma bubbles, $\mathrm{J}$. Geophys. Res., 89, 10903-10912, 1984.

Mendillo, M. and Baumgardner, J.: Airglow characteristics of equatorial plasma depletions, J. Geophys. Res., 87, 7641-7652, 1982.

Paulson, M. R.: Scintillation of VHF/UHF and L band satellite signals at Guam, Radio Sci., 16, 877-884, 1981.

Röttger, J.: Wave-like structures of large-scale equatorial spread-F irregularities, J. Atmos. Terr. Phys., 35, 1195-1206, 1973.

Röttger, J.: The macro-scale structure of equatorial spread-F irregularities, J. Atmos. Terr. Phys., 38, 97-101, 1976.

Schmidt, R. O.: Multiple emitter location and signal parameter estimation, IEEE Trans. Antennas Propagat., AP-34, 276-280, 1986.

Tanohata, K., Kuriki, I., Iguchi, M., Yamashita, K., and Sakamoto, T.: The results of long-term experiment of trans-equatorial VHF wave propagation, Rev. Radio Res. Lab. (in Japanese), 26, 885897, 1980.
Tsunoda, R. T. and White, B. R.: On the generation and growth of equatorial backscatter plumes, 1 . Wave structure in the bottomside F layer, J. Geophys. Rs., 86, 3610-3616, 1981.

Tsunoda, R. T.: On the generation and growth of equatorial backscatter plumes, 2. Structuring of the west walls of upwellings, J. Geophys. Res., 88, 4869-4874, 1983.

Tsunoda, R. T., Livingston, R. C., McClure, J. P., and Hanson, W. B.: Equatorial plasma bubbles: Vertically elongated wedges from the bottomside F layer, J. Geophys. Res., 87, 9171-9180, 1982.

Weber, E. J., Buchau, J., and Moore, J. G.: Airborne studies of equatorial F layer ionospheric irregularities, J. Geophys. Res., 85, 4631-4641, 1980.

Weber, E. J., Brinton, H. C., Buchau, J., and Moore, J. G.: Coordinated airborne and satellite measurements of equatorial plasma depletions, J. Geophys. Res., 87, 10 503-10 513, 1982.

Yokoyama, T., Fukao, S., and Yamamoto, M.: Relationship of the onset of equatorial $\mathrm{F}$ region irregularities with the sunset terminator observed with the Equatorial Atmosphere Radar, Geophys. Res. Let., 31, L24804, doi:10.1029/2004GL021529, 2004. 